“C 2018 IEEE. Personal use of this material is permitted. Permission from IEEE must be obtained for all other uses, in any current or future media, including reprinting/republishing this material for advertising or promotional purposes, creating new collective works, for resale or redistribution to servers or lists, or reuse of any copyrighted component of this work in other works." 


\title{
Miniaturized Multibeam Array Antenna Based on E-Plane Butler Matrix for 5G Application
}

\author{
Ji-Wei Lian, Yong-Ling Ban, You-Quan Wu and Le-Hao Zhong \\ School of Electronic Engineering \\ University of Electronic Science and Technology of China (UESTC) \\ Chengdu, Sichuan, China \\ lianjiwei@std.uestc.edu.cn, byl@uestc.edu.cn
}

\begin{abstract}
A miniaturized multibeam array antenna fed by a compact beam-forming network (BFN) in multi-layer substrate integrated waveguide (SIW) technology is addressed. As the BFN, an E-plane $4 \times 4$ Butler matrix $(B M)$ is designed. It is stacked with basic components in the vertical direction so that the dimension can be significantly reduced. Furthermore, some modifications of the BM have been made to obtain further miniaturization. The total occupied area of the designed antenna, including the BFN, is merely $3.8 \lambda \times 0.5 \lambda$, which provides an attractive alternative for future 5G applications.
\end{abstract}

Index Terms-miniaturization, Butler matrix (BM), multibeam application, substrate integrated waveguide (SIW), 5G.

\section{INTRODUCTION}

$\mathrm{T}^{0}$ $\mathrm{O}$ adapt to the ever-growing wireless data rate demands, the development of the millimeter-wave multibeam array antenna technology have triggered widespread attentions, especially in the coming fifth-generation (5G) mobile communication systems. Butler matrix (BM) [1]-[7] is a very popular beam-forming network (BFN) for multibeam application because of its relatively balanced transmission properties and flexible configuration.

Nevertheless, BM faces an inevitable challenge, namely, the relatively large circuit size. The practical solution for space saving is to use the multi-layered technology [3]-[7]. In this paper, a miniaturized multibeam array antenna based on E-plane 4-way BM is proposed. Different from other $\mathrm{BM}$, the E-plane BM is constituted by basic components in the vertical direction, making the BFN hidden underneath the array possible.

\section{DESIGN PROCESS}

\section{A. Topology of E-plane $4 \times 4$ BM}

A conventional 4-way BM is composed of four hybrid couplers and four fixed phase shifters. Crossovers are also required to address the intersections of transmission paths. As counterpart, the E-plane $4 \times 4 \mathrm{BM}$ is formed in a similar way but in the different plane. The detailed topology of the proposed E-plane 4-way BM is described in Fig. 1. Obviously, the E-plane 4-way BM is obtained by the combination of four E-plane hybrid couplers, two E-plane crossovers and four fixed phase shifters. Unlike the H-plane $\mathrm{BM}$, the basic components of the E-plane BM are vertically stacked so that the electromagnetic wave is able to travel across separate layers, which can remarkably decrease the

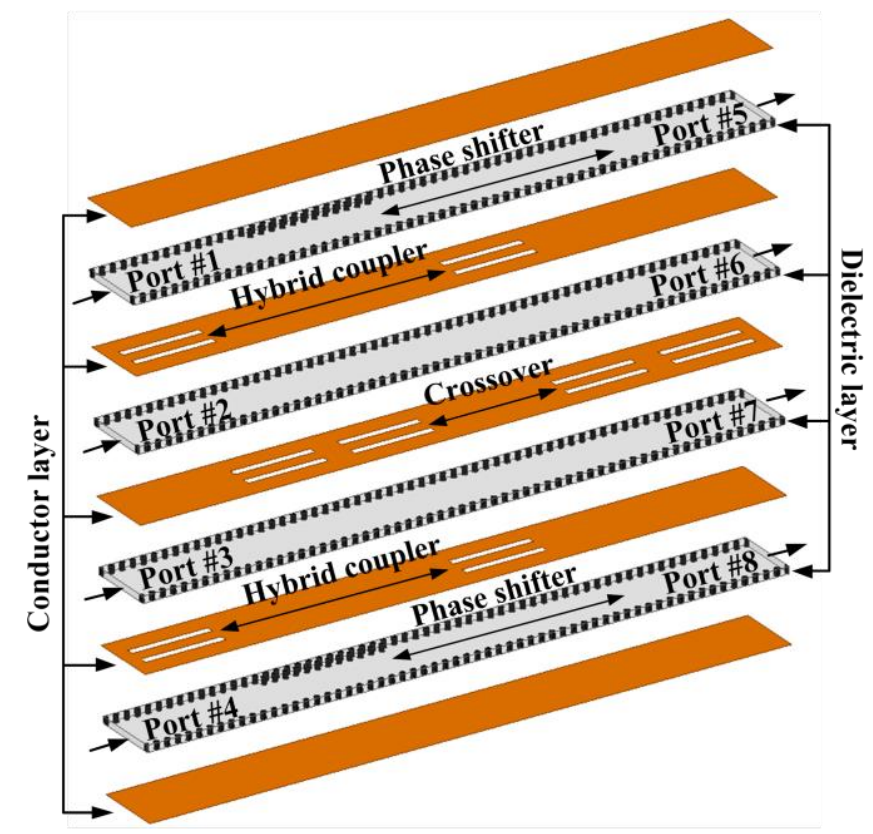

Fig. 1. Configuration of the proposed E-plane $4 \times 4$ BM.
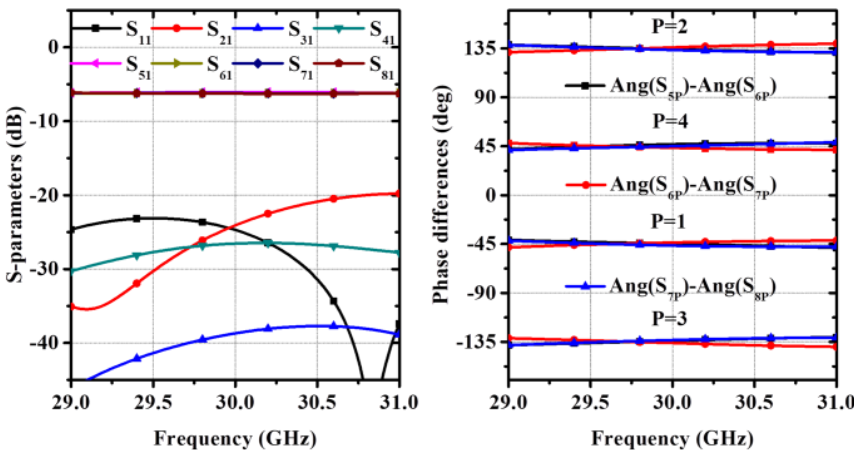

Fig. 2. Simulated S-parameters for port \#1 excitation and phase differences of the E-plane $4 \times 4 \mathrm{BM}$.

width of the BM. The additionally introduced E-plane crossover is formed by two cascaded E-plane hybrid couplers. The overall structure of the E-plane 4-way BM is composed of four substrates with dimensions of $0.5 \lambda \times 4.8$ $\lambda$. Four input ports \#1-\#4 are assigned to the left side while output ports \#5-\#8 to the right side.

\section{B. Performance}

The simulated results of the proposed E-plane 4-way BM are plotted in Fig. 2. As is depicted, the reflection and isolation coefficients are less than $-20 \mathrm{~dB}$ within the 


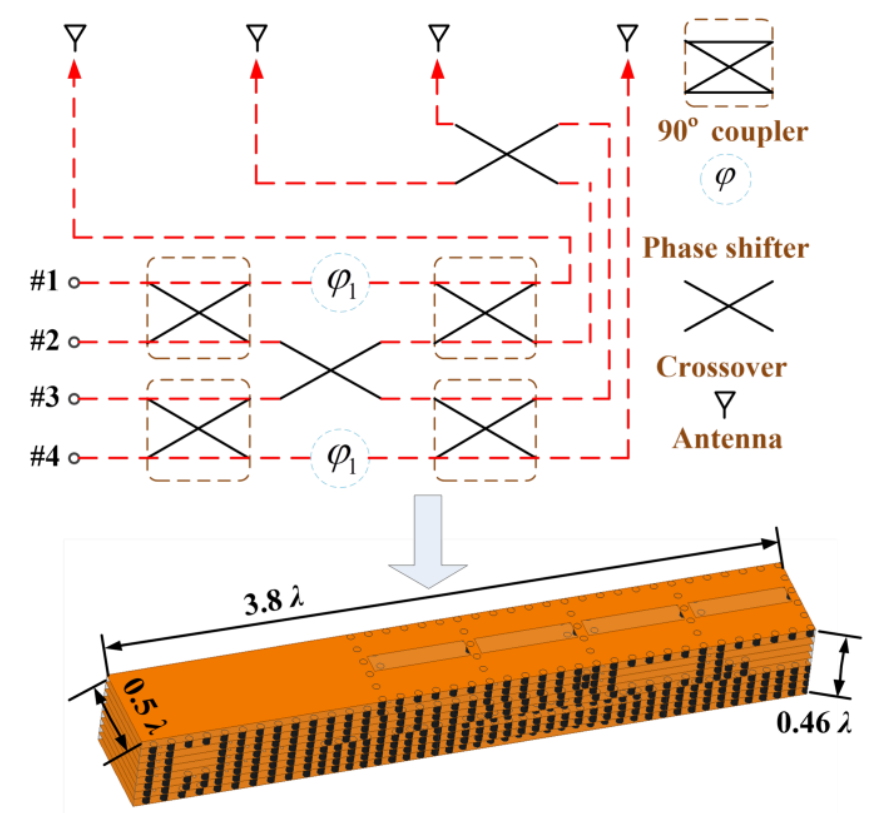

Fig. 3. Topology and simulated model of the multibeam array antenna.

operating band (29 GHz to $31 \mathrm{GHz}$ ). The transmission coefficients are observed with amplitude ripples of \pm 0.15 $\mathrm{dB}$ near $-6.1 \mathrm{~dB}$ at the center frequency.

Fig. 2(b) displays well-balanced phase differences between adjacent output ports, i.e., $\operatorname{ang}\left(\mathrm{S}_{5 \mathrm{P}}\right)-\operatorname{ang}\left(\mathrm{S}_{6 \mathrm{P}}\right)$, $\operatorname{ang}\left(\mathrm{S}_{6 \mathrm{P}}\right)-\left(\mathrm{S}_{7 \mathrm{P}}\right)$, ang $\left(\mathrm{S}_{7 \mathrm{P}}\right)-\operatorname{ang}\left(\mathrm{S}_{8 \mathrm{P}}\right)$ are observed with slight fluctuations around $-45^{\circ}, 135^{\circ},-135^{\circ}$, and $45^{\circ}$ for excitations from port \#1 to \#4 (noted as $\mathrm{P}=1$ to 4), respectively. From 29 to $31 \mathrm{GHz}$, the phase peak-to-peak errors are less than $\pm 5^{\circ}$.

\section{Multibeam array}

With applying the E-plane BM, a miniaturized multibeam array can be realized. In order to achieve better compactness, some modifications are conducted here. The detailed topology and simulated model are exhibited in Figs. 2 and 3. Firstly, the array is put at the top of the BFN so that the BFN can be hidden underneath the array. Also, a transition network is designed for the conjunction of the Eplane BM and the array. Secondly, one set of the crossovers is embedded into the transition network to further reduce the total length.

\section{Simulated Results}

Both the reflection and isolation coefficients are below $-10 \mathrm{~dB}$ within the frequency band $(29-31 \mathrm{GHz})$. The radiation patterns are shown in Fig. 4. Operating at the center frequency of $30 \mathrm{GHz}$, the pointing directions of the four generated beams are $-34^{\circ},-11^{\circ}, 12^{\circ}$, and $34^{\circ}$. The 3$\mathrm{dB}$ scanning range of the proposed multibeam antenna is approximately $\pm 43^{\circ}$. The simulated gains associated with port \#1 to port \#4 excitations are $11.6 \mathrm{dBi}, 10.4 \mathrm{dBi}, 10.2$ $\mathrm{dBi}$, and $11.8 \mathrm{dBi}$, respectively. The corresponding crosspolarization levels are $-31 \mathrm{~dB},-26.9 \mathrm{~dB},-27.2 \mathrm{~dB}$, and $28.9 \mathrm{~dB}$, respectively.

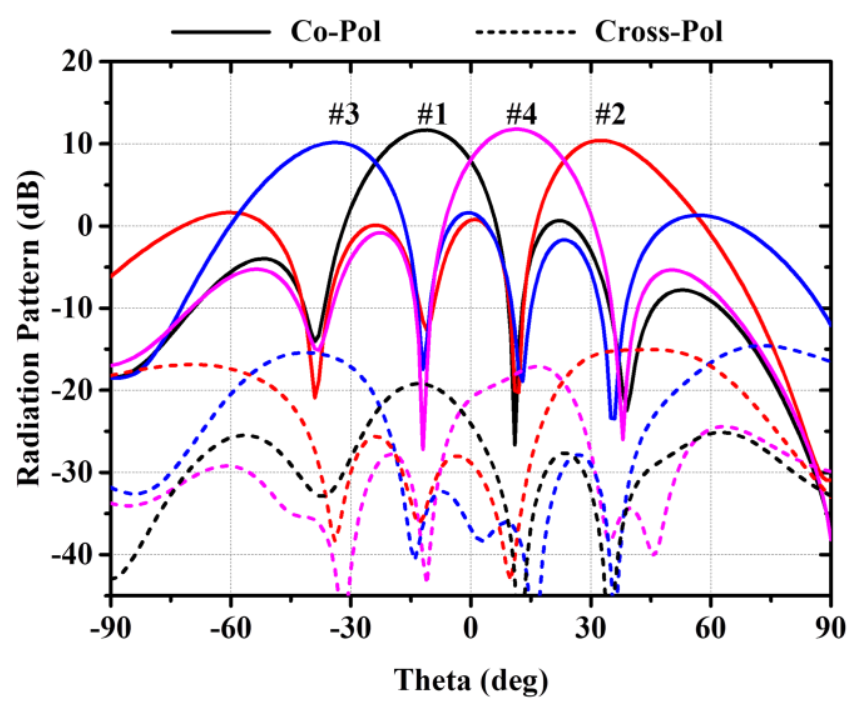

Fig. 4. Simulated radiation patterns at $30 \mathrm{GHz}$.

\section{CONCLUSION}

In this paper, a miniaturized multibeam array antenna fed by a novel E-plane $4 \times 4 \mathrm{BM}$ is proposed. The E-plane $4 \times$ $4 \mathrm{BM}$ is proposed to reduce the occupied area. Furthermore, some modifications of the BFN are made to achieve better compactness. As the data shown, within the frequency band from 29 to $31 \mathrm{GHz}$, reflection and isolation coefficients are less than $-10 \mathrm{~dB}$, the realized gains for excitations from port \#1 to port \#4 at $30 \mathrm{GHz}$ are $11.6 \mathrm{dBi}, 10.4 \mathrm{dBi}, 10.2$ $\mathrm{dBi}$, and $11.8 \mathrm{dBi}$, respectively, and the scanning range is approximately $\pm 43^{\circ}$. The total multibeam scheme amounts to cover an area of $0.46 \lambda \times 0.5 \lambda \times 3.8 \lambda$, which is promising for $5 \mathrm{G}$ applications.

\section{REFERENCES}

[1] Q.-L. Yang, Y.-L. Ban, K. Kang, C.-Y.-D. Sim and G. Wu, "SIW multibeam array for $5 \mathrm{G}$ mobile devices," IEEE Access, vol. 4, pp. 2788-2796, Jun. 2016.

[2] Q.-L. Yang, Y.-L. Ban, J.-W. Lian, Z.-F. Yu and B. Wu, "SIW Butler matrix with modified hybrid coupler for slot antenna array," IEEE Access, vol. 4, pp. 9561-9569, Dec. 2016.

[3] L.-H. Zhong, Y.-L. Ban, J.-W. Lian, Q.-L. Yang, J. Guo and Z.-F. Yu, "Miniaturized SIW multibeam antenna array fed by dual-layer $8 \times 8$ Butler matrix," IEEE Antennas Wireless Propag. Lett., vol. 16, pp. 3018-3021, 2017.

[4] A. A. M. Ali, N. J. G. Fonseca, F. Coccetti and H. Aubert, "Design and implementation of two-layer compact wideband Butler matrices in SIW technology for Ku-band applications," IEEE Trans. Antennas Propag., vol. 59, no. 2, pp. 503-512, Nov. 2010.

[5] Y. J. Cheng, X. Y. Bao and Y. X. Guo, "60-GHz LTCC miniaturized substrate integrated multibeam array antenna with multiple polarizations," IEEE Trans. Antennas Propag., vol. 61, no. 12, pp. 5958-5967, Sep. 2013.

[6] J. Wang, Y. Li, L. Ge, J. Wang and K.-M Luk, "A 60-GHz horizontally polarized magnetoelectric dipole antenna array with 2-D multi-beam end-fire radiation," IEEE Trans. Antennas Propag., vol. 65 , no. 11 , pp. 5837-5845, Nov. 2017.

[7] W. Yang, Y. Yang, W. Che, C. Fan and Q. Xue, "94-GHz compact two-dimensional multi-beam LTCC antenna based on multifolded SIW beam-forming network," IEEE Trans. Antennas Propag., vol. 65, no. 8, pp. 4328-4333, Aug. 2017. 